revista ANTHROPOLÓGICAS

Ano 22, 29(2):28-48, 2018

\title{
Cuidado, Velhice, Gênero e Deficiência Social: Algumas reflexões
}

Marcia Reis Longhi ${ }^{\mathrm{a}}$

O presente texto tem o objetivo de tecer algumas considerações a partir do entrelaçamento das categorias cuidado, velhice, gênero, deficiência social e território. A inspiração vem do trabalho de campo realizado em uma comunidade do município de Lucena (PB) e da observação realizada em uma instituição-dia para idosos, também localizada em Lucena. A partir de algumas reflexões provocadas pelo fato de existir uma instituição para idosos numa área próxima do rural, problematizo algumas pré-noções sobre a velhice e diante da diversidade apresentada pelas interlocutoras e da riqueza da literatura, concluo propondo repensarmos sobre a categoria cuidado e ampliarmos as possibilidades de definição de velhice ${ }^{1}$.

Cuidado, Velhice, Gênero, Deficiência.

No que diz respeito às ciências sociais, o cuidado, já há algumas décadas, vem sendo tema de reflexões acadêmicas. Estudos (nacionais e internacionais) sobre família, numa abordagem feminista, mostram que 'o cuidar' é uma atividade vista, de forma naturalizada, como feminina, familiar, geralmente invisibilizada e com discussões praticamente inexistentes no campo da política. Dialogando com os marcadores sociais gênero, classe, raça e geração, as discussões revelam uma realidade que incide diretamente na divisão sexual do trabalho

a Professora adjunta do DCS/UFPB; membro permanente do PPGA/UFPB. E-mail: marciareislonghi@gmail.com. 
na sociedade ocidental moderna e seus desdobramentos, geralmente nefastos, no que diz respeito às desigualdades de gênero.

Mais recentemente, diante da realidade inegável e irreversível no que diz respeito ao envelhecimento populacional, tanto nos países chamados desenvolvidos como naqueles em desenvolvimento, e, por outro lado, frente as transformações da sociedade com o crescente ingresso das mulheres no mercado de trabalho, impactando inclusive e fortemente na dinâmica familiar e na queda da fecundidade, tem crescido muito a produção que reflete sobre envelhecimento e cuidado e as repercussões deste nova configuração demográfica na organização social.

No Brasil, a literatura ainda não tão vasta, mas bastante consistente, tem versado, entre outros temas, sobre cuidados e cuidadoras (Camarano 2005 e 2010; Sorj \& Fontes 2012; Debert 1999 e 2016; Hirata, Guimarães \& Sugita 2011, entre outras), reafirmando a feminilização do cuidar e a responsabilização do núcleo familiar por seus idosos. As pesquisas também se debruçam sobre as políticas públicas para idosos e a participação do Estado no tripé composto pela Família, Estado e Mercado (Instituições privadas, comunitárias ou remuneradas). Alguns autores (Camarano 2010; Camarano \& Medeiros 1999) estudam o sistema previdenciário, as políticas assistenciais de transferência de renda e os efeitos destes sobre a qualidade de vida dos idosos e seus efeitos nas relações intergeracionais. Estudos mais recentes se propõem discutir sobre uma política feminista do cuidado (Zirbel 2016).

Como podemos perceber, no campo acadêmico existe um crescente interesse nesta discussão, que se confirma pelo recente congresso internacional que aconteceu no início de novembro deste ano, no Uruguai, 'Miradas Latinoamericanas al cuidado: Primer Congreso latinoamericano de Estudios de Género y Cuidados', no qual se inscreveram mais de 200 pessoas, de diferentes países e de onde saiu a proposta de uma Rede Latinoamericana de estudos sobre o cuidado e a proposta de um segundo congresso a ser realizado em 2020 muito provavelmente na Colômbia. 
O presente texto tem a intenção de contribuir modestamente com esta discussão tecendo algumas considerações sobre o entrelaçamento, quase inevitável, das categorias velhice, gênero, cuidado e deficiência, a partir de uma realidade específica. A discussão se dá amparada no trabalho de campo realizado entre 2015 e 2016 numa comunidade do município de Lucena, na Paraíba, Brasil. A categoria 'deficiência' será utilizada a partir da ideia de deficiência social que vem sendo discutida por alguns autores, entre eles Débora Diniz, Marcelo Medeiros e Lívia Barbosa (2010), nos quais me inspiro neste momento.

O texto será organizado da seguinte forma: além desta pequena introdução, farei o enquadramento do campo, descreverei o público alvo e a dinâmica da instituição e em seguida farei algumas problematizações sobre território, dependência e independência e deficiência social. A intenção é fazer algumas provocações e pensar sobre a complexidade da categoria velhice. ${ }^{2}$

Tomar conhecimento da existência da 'Casa do Vô João', já me soou como uma provocação (de pesquisa). Sem ter nenhuma informação sobre seu funcionamento, sobre sua história e sem saber com exatidão sua localização, descobrir que existia um lar para idosos nas vizinhanças da Comunidade da Guia (Lucena/PB) já me pareceu algo estranho, deslocado... No mínimo curioso.

Mas, naquele momento - meados de 2013 - ainda não estava interessada em estudar a relação entre 'cuidado e velhice' e o estranhamento inicial foi, lentamente, perdendo espaço no meu campo de prioridades. Algum tempo depois, ao longo de 2014, o cuidado como categoria que permeia as relações inter-geracionais ganhou destaque entre minhas preocupações acadêmicas e tornou-se o foco do projeto que submeti ao edital universal 2014/2015, posteriormente aprovado. Neste projeto elegi a comunidade da Guia, como meu lócus de pesquisa. Propus-me pensar a construção de sentido a partir das rela- 
ções de cuidado entre as diferentes gerações. A diminuta extensão da Comunidade e o fato de sua população ser composta por apenas dois grandes ramos familiares fazia da Guia o lugar ideal para observar a práxis do cuidado e a intersubjetividade envolvida. Este novo contexto recoloca o Lar de Idosos no meu campo de visão e de possibilidades de pesquisa. Foi assim que conheci e comecei a frequentar o lar, em novembro de 2014.

Mas, afinal, porque o lar me provocou antes mesmo de se tornar fisicamente real?

Vamos lá...

Não sei ao certo qual dado tomou a dianteira: se a existência de uma instituição para idosos num espaço físico com aquelas características - isolado, no meio do 'nada' - ou se o fato de existir público para tal instituição. Ambas as ponderações num primeiro momento falam apenas do senso comum e dão indícios do tipo de representações sociais que permeiam por um lado o envelhecimento e a figura do idoso e por outro as (pré)noções que colam a determinados espaços físicos.

Mais ou menos isso: Qual a necessidade de uma casa para idosos 'no meio do mato'? Por trás desta dúvida se escondem alguns préconceitos:

1. São os grandes centros urbanos, com sua dinâmica cotidiana, corrida e estressante, e seus espaços de moradia cada vez mais reduzidos, que precisam se preocupar com a velhice e em criar estruturas que dêem conta da população idosa 'dependente';

2. Em espaços 'rurais' existe uma divisão particular do tempo social e os familiares podem cuidar de seus idosos;

3. Os idosos só vão para uma casa de acolhimento se seus familiares não puderem ficar com eles; não é uma escolha;

4. Quem mora em espaços rurais sempre tem espaço físico para receber seus idosos.

Estimulada por estas inquietações resolvo conhecer a instituição. Em outro trabalho teço algumas reflexões sobre os conceitos de rural e urbano numa perspectiva das ciências sociais, mas não irei incluí-las neste texto por considerar que fogem da discussão principal neste mo- 
mento. ${ }^{4}$ Mas, permanece a questão: o que pensamos sobre um lar para idosos e sobre os idosos que o frequentam? As narrativas de alguns idosos nos provocaram e embaralharam concepções mais ou menos estabelecidas sobre velhice, relações familiares, cuidado, localidade e casas de acolhimento.

Numa tentativa de organizar o pensamento, irei inicialmente situar espacialmente a instituição e fazer uma breve descrição da mesma. Em seguida, trarei alguns dados que podem nos mostrar o que a antropologia (pouco) tem discutido quando nos propomos entrelaçar envelhecimento e território.

\section{A instituição}

A ‘Casa do Vô João’ fica no município de Lucena (PB), mais precisamente no distrito de Costinha, próximo da comunidade da Guia. Lucena localiza-se na região metropolitana de João Pessoa, Paraíba e de acordo com o IBGE, sua população em 2010 era de 11.730 habitantes e a população estimada de 2014, 12.630, distribuídos nos $88,549 \mathrm{Km} 2$ de área. O município é composto pelos distritos de Costinha, Fagundes e Lucena (Centro), onde concentra-se a maior parte do aparelhamento público: prefeitura, escolas, secretarias, etc.

$\mathrm{O}$ acesso ao município pode acontecer através da utilização da balsa, que sai de hora em hora da região portuária de Cabedelo (PB) e que é o transporte mais usado pela população, por ser mais rápido e barato $^{5}$; ou pelas rodovias estaduais PB-008, PB-025 e PB-019. Ambas as possibilidades contribuem com a sensação de estarmos nos distanciando da área urbana e nos aproximando de uma região que, se não é rural também não é cidade, com exceção do centro de Lucena que tem de fato o perfil de um pequeno centro urbano (trânsito, muitos transeuntes pelas calçadas, muitos estabelecimentos comerciais).

Se escolhermos chegar de balsa, vamos, lentamente, nos afastando do porto e nos aproximando de uma área com poucas habitações. Se optarmos pela via terrestre, parte do trajeto se dará no meio de canaviais, seguido de um vasto coqueiral, até chegarmos no primeiro 
aglomerado de casas. Enfim, estamos falando de uma região de grande beleza natural e baixa densidade demográfica.

A 'Casa do Vô João' fica às margens da via principal que atravessa todo município. A Instituição é uma iniciativa privada, sem fins lucrativos, que tem parceria com a prefeitura de Lucena. $\mathrm{O}$ terreno e a casa são propriedades de um empresário de João Pessoa, que resolveu construir o lar "para ajudar os idosos da região que não dispõem de recursos econômicos e que não têm apoio da família" ${ }^{6}$.. $\bigcirc$ proprietário mantém a casa, paga uma funcionária para supervisionar o lar e uma cozinheira e conta com a ajuda de amigos empresários que doam mensalmente cestas básicas. A prefeitura, por sua vez, entra com os demais funcionários [duas cuidadoras, uma auxiliar de serviços gerais, uma auxiliar de enfermagem] e o ônibus [e o motorista] que pega os idosos no início do dia e os reconduzem às suas casas no final da tarde. Trata-se de uma instituição-dia. As funcionárias eram todas mulheres, com exceção do motorista, confirmando o que mostra a literatura: o cuidado, mesmo o remunerado, é uma atividade exercida majoritariamente por mulheres.

A casa recebe pessoas que tenham 60 anos ou mais, homens e mulheres, que morem no município. A proposta da instituição é receber apenas pessoas fisicamente independentes, que dêem conta das Atividades da Vida Diária (AVD), pois não dispõe de estrutura e pessoal capacitado para acolher uma demanda que exija cuidados mais especializados. No entanto, no período que frequentamos o lar (eu e uma aluna) havia uma senhora amputada (decorrência de complicações da diabetes) e outra, que era na palavra deles, 'meio perturbada'. A justificativa que deram quando perguntamos o porque daquelas usuárias, apesar das regras previamente ditas, foi que "não tiveram como recusar". Os demais frequentadores são, considerando a definição técnica, fisicamente independentes - esta questão será retomada mais adiante. Não existe a obrigatoriedade de visitar o lar diariamente, mas caso alguém se ausente por 30 dias seguidos, a vaga é preenchida por outra pessoa. 
No momento da pesquisa existiam 50 inscritos, que corresponde à lotação máxima da instituição. O público era predominantemente feminino, em torno de $80 \%$. Algumas são casadas, outras viúvas e outras solteiras. A grande maioria mora com familiares, geralmente filhas, mas há também as que moram sozinhas, ou com seus companheiros. Todas e todos eram pessoas simples, mas nenhuma era miserável. Encontramos idosas que recém tinham completado 60 anos e outras que já haviam passado dos noventa, mas a maioria estava na faixa entre 65-75 anos.

Este fato merece algumas ponderações. A realidade encontrada no lar reflete, com algumas ressalvas, a realidade macro. Não só a população está envelhecendo, no sentido que estamos tendo, proporcionalmente, um número maior de idosos e menor de crianças a cada ano, como os idosos estão vivendo mais. Isto significa que dentro de uma mesma categoria etária encontramos pessoas com até 30 anos de diferença, como se verifica na casa do Vô João. Os idosos denominados 'mais idosos' são aqueles que tem 80 anos ou mais e os dados do IBGE mostram que é um segmento que vem crescendo numericamente. É de se esperar que estas pessoas, mesmo não sendo consideradas dependentes demandem um tipo de atenção diferenciada. Pudemos observar, entre as idosas que frequentavam o lar, que existia uma rede de cuidados entre as próprias usuárias. As mais jovens atuavam como apoiadoras das mais velhas: uma pequena ajuda na hora de levantar da cadeira, um apoio na hora que não escutavam alguma coisa que eu perguntava ou que estava sendo dito na televisão, enfim, reproduzindo a lógica familiar de cuidados, as mulheres se cuidavam entre si, mesmo estando numa instituição de cuidados.

Este tipo de instituição tem sido uma das alternativas diante da nova configuração social. As mulheres, tradicionalmente as cuidadoras familiares, estão cada vez mais inseridas no mercado de trabalho e não dispõem de tempo para suprir todas as necessidades de cuidado dos integrantes do núcleo familiar, principalmente as crianças e os idosos. Considerando que o Estado também não incorpora plenamente 
esta demanda, existem Instituições filantrópicas, sem fins lucrativos ou mistas que suprem, em parte, o vácuo deixado pela assistência social na atual lógica neo liberal (Sorj \& Fontes 2012). Assim, como a literatura tem mostrado, alguns lógicas se mantém: as cuidadoras são todas mulheres, oriundas de classes sociais economicamente desprivilegiadas e na maior parte das vezes sem uma especialização que as capacite para lidar com as demandas deste segmento etário.

Também é importante ressaltarmos a predominância de mulheres entre os usuários. Estudos mostram que são mais mulheres do que homens que são assistidas por instituições de cuidado, inclusive aquelas de Permanência de Longa Duração. De acordo com Camarano (2010) as mulheres são aproximadamente 57,6 \% das residentes neste tipo de instituição. Também de acordo com a literatura, as mulheres, apesar de viverem mais, são as que passam por períodos mais longos de necessidades de cuidado.

No que diz respeito as motivações para estarem ali, encontramos situações variadas. É importante destacar que a maioria, diferentemente das fantasias iniciais da pesquisadora, procurou a instituição por vontade própria. Um número significativo alegou se sentir muito só em casa (mesmo morando com familiares); outras, em torno de um terço das usuárias, afirmaram se sentir mais seguras na instituição, pois caso tivessem algum problema de saúde seriam rapidamente socorridas. Mas também encontramos idosas que afirmaram estar ali para se afastar, pelo menos temporariamente, dos problemas familiares. Uma delas disse que ir para o lar era uma forma de se sentir ativa, era como ir para o trabalho, pois impunha uma rotina: ter horário para acordar, ter que se arrumar para sair de casa, encontrar pessoas, enfim, mas do que ser cuidada ela queria se sentir acolhida e fazendo parte de um grupo. No lar ela poderia ser confundida com uma das cuidadoras, pois estava sempre dando um suporte emocional ou físico para as senhoras mais idosas.

Quando perguntamos o que gostavam mais na casa-dia, a grande maioria disse que gostava das atividades de lazer, dos passeios e dos 
amigos e amigas que faziam. Novamente, diferentemente do que havia imaginado, apesar do lar estar situado em um espaço com características rurais, os idosos e as idosas, na sua maioria, não eram trabalhadoras rurais e seus filhos e filhas trabalhavam em atividades diversas.

Aqui também cabem algumas reflexões. A literatura nacional e internacional mostra que as idosas permanecem desempenhando atividades de cuidados informais, em geral dentro da rede familiar (Camarano 2003 e 2005; Palomo \& Terrón 2015). Esta realidade também foi muito observada no etnografia da Guia (Longhi 2018). Neste sentido, o fato de algumas frequentadoras do lar de idosos afirmarem que foram para lá para não terem que "ficar em casa resolvendo problemas" só confirma os dados. Uma senhora, durante nossa conversa, conta que inclusive deixa o celular desligado, pois caso contrário o filho, já adulto, separado e responsável por um pequeno negócio que eles têm na própria casa, não para de ligar. O lar, para algumas, é mais um refúgio e um centro de lazer do que uma instituição de cuidado. Também merece reflexão a fala da senhora que vê o lar como um compromisso social que a obriga a manter uma rotina de trabalho. Esta senhora era parteira e nos últimos anos havia trabalhado no posto de saúde. Sempre teve uma vida muito dinâmica. Agora estava aposentada, mas considerava fundamental seguir organizando seu tempo a partir da lógica temporal do trabalho. Podemos perceber que estas mulheres permanecem sendo cuidadoras em suas redes familiares, ocupando, simultaneamente, o lugar de cuidadas e de cuidadoras, fato que também foi observado entre as idosas da Guia.

\section{Algumas reflexões sobre território}

Nas palavras de Ricardo Abramovay,

"há um vício de raciocínio na maneira como se definem as áreas rurais no Brasil, que contribui decisivamente para que sejam assimiladas automaticamente a atraso, carência de serviços e falta de cidadania. A definição do IBGE, para usar a expressão de Elena Saraceno (1996/1999), é de natureza residual: as áreas rurais são aquelas 
que se encontram fora dos limites das cidades, cujo estabelecimento é prerrogativa das prefeituras municipais. $\mathrm{O}$ acesso a infra-estruturas e serviços básicos e um mínimo de adensamento são suficientes para que a população se torne 'urbana'. Com isso, o meio rural corresponde aos remanescentes ainda não atingidos pelas cidades e sua emancipação social passa a ser vista - de maneira distorcida - como "urbanização do campo" (Abramovay 2003:9).

Ainda existe no imaginário social uma concepção de inspiração evolucionista que vê o rural como algo atrasado, com ritmo mais calmo, forma de viver mais convencional, onde as pessoas são mais solidárias, onde existe menos violência, indicando um momento anterior ao que é próprio da urbanidade. Nesta perspectiva, o rural caminha para seu fim rumo à cidade, ícone da modernidade. No entanto, estudos mostram que esta realidade é bem mais complexa e que não estamos falando de diferentes momentos da 'evolução social', mas sim de diferentes contextos, com dinâmicas próprias e igualmente contemporâneos.Nesta perspectiva "o fim da dicotomia rural-urbano busca qualificar realidades sociais distintas nas sociedades contemporâneas" (Carneiro 2008:13). Seguindo este raciocínio, é pertinente nos debruçarmos sobre os sentidos construídos pelas idosas que freqüentam uma instituição que está, oficialmente, situada numa área urbana, mas com características rurais. Poderemos, assim, contribuir com novas compreensões desta realidade, diminuindo o desconhecimento e as visões estereotipadas.

Outra questão que merece ser evidenciada é o fato de que organismos internacionais e também ações governamentais atrelam urbanização e envelhecimento, como mostraremos em seguida.

\section{Urbanização e envelhecimento}

De acordo com a Organização Mundial de Saúde (2008) "O envelhecimento populacional e a urbanização são duas tendências mundiais que, em conjunto, representam as maiores forças que moldam o século XXI" (OMS 2008:7). É evidente o crescimento dos centros urbanos e também é estatisticamente comprovado o aumento do con- 
tingente populacional de pessoas com 60 anos ou mais. Num período relativamente curto, a humanidade, pela primeira vez na história, terá mais velhos do que crianças. Os números também indicam que os países em desenvolvimento estão envelhecendo mais rapidamente que os países desenvolvidos. Estes dados falam do 'sucesso' da humanidade. A estimativa de vida vem aumentando significativamente, decorrência dos avanços científicos, das políticas públicas de saúde e do acesso da população aos aparatos de proteção.

Por outro lado, a transformação do perfil demográfico mundial e também no Brasil obriga que o poder público se debruce sobre esta realidade e pense em estratégias políticas, econômicas e sociais para lidar com algo que já é fato: a população está envelhecendo e, paralelamente, o índice de natalidade vem caindo o que anuncia uma nova realidade em um período relativamente curto.

Os dados, no entanto, nos mostram algumas contradições. Se, por um lado, os estudos sobre envelhecimento não priorizam, e muitas vezes desconsideram o território, por outro, quando nos debruçamos sobre documentos internacionais encontramos iniciativas voltadas justamente para espaços saudáveis, inclusive projetos de cidades voltadas especificamente para este segmento social. A Organização Mundial de Saúde (OMS) lançou, em 2008, o 'Guia Global: cidade amiga do idoso'. O projeto foi implementado em 33 cidades, com amostras em todos os continentes. Foram feitos grupos focais e entrevistas com idosos e também com cuidadores/cuidadoras e profissionais da área da saúde. A partir do material, elaborou-se um guia com recomendações de ações que poderiam contribuir com a qualidade de vida dos idosos. A proposta procurou abranger as mais variadas dimensões da vida e também, claro, o aparato urbano. Espaços abertos e prédios, transportes, moradia, participação social, segurança, foram alguns dos itens selecionados. A partir dos resultados, a OMS elaborou um manual que visa orientar as administrações públicas sobre os indicadores que devem ser priorizados para tornar as cidades espaços adequados para a população idosa. 
Chama atenção o fato de que alguns elementos sempre são lembrados quando o público alvo é a terceira idade: assistência médica, acessibilidade, envolvimento em atividades físicas e de lazer. Todos estes itens indicam que a ênfase está nas limitações que a idade impõe e na proposta de promover o envelhecimento ativo (OMS 2005) como paradigma fundamental. Envelhecer, nesta perspectiva, significa, predominantemente, ter suas funções físicas e mentais limitadas e sendo assim precisar de aparatos que minimizem as debilidades próprias da idade. Existe o lado positivo desta visão. Muitas idosas precisam realmente de acompanhamento médico e de aparatos que viabilizem sua locomoção com segurança e autonomia. No entanto, se pensarmos que idosa é aquela pessoa que tem 60 anos ou mais, podemos pensar que na contemporaneidade e nos grandes centros muitos dos que se encontram nesta faixa ainda vão viver muitos anos com autonomia e independência e o que eles precisam são estimulo e aparato institucional para se manterem saudáveis e produtivos. "Seguindo a abordagem da OMS para o envelhecimento ativo, o objetivo deste Guia é mobilizar cidades para que se tornem mais amigas do idoso, para poderem usufruir o potencial que os idosos representam para a humanidade" (Guia Global: cidade amiga do idoso).

No entanto, apesar das recomendações dos órgãos internacionais, não podemos dizer que exista uma real preocupação dos estados em incrementar políticas públicas que promovam a inclusão da população mais idosa. Igualmente não encontramos, salvo algumas exceções, estados empenhados em incrementar políticas de cuidado.

No que diz respeito a população brasileira, os dados demográficos mostram que em menos de um século a expectativa de vida aumentou significativamente. Se no início do século XX, a esperança de vida do brasileiro não passava dos 33,5 anos, em 2010 foi para 73,5 (76,3 anos, no caso das mulheres, e 69,1 anos, para os homens). A Pesquisa Nacional por Amostra de Domicílios, a PNAD 2009 (IBGE 2010), revela que a proporção de idosos passou de $9,1 \%$ do total em 1999 para 11,3\% em 2009, o que significa, hoje, a existência de mais de 22 milhões de 
brasileiras e brasileiros acima de 60 anos. (IBGE 2010; Minayo 2011). Podemos dizer que estamos falando de um contingente populacional que irá viver com este status muito provavelmente por pelo menos 30 anos. Sendo assim, é uma questão que prende a atenção de demógrafos, mas principalmente de governos, que precisam pensar como estas pessoas irão viver, tanto do ponto de vista econômico, quanto do ponto de vista da saúde e das relações sociais.

De acordo com o que foi anteriormente colocado, existem vários estudos sobre instituições de longa duração e sobre idosos que demandam cuidados para realizar as Atividades da Vida Diária (Camarano 2010); questões extremamente relevantes e preocupantes, que remetem às reflexões sobre previdência privada e políticas de cuidado. No entanto, neste momento meu objetivo é chamar atenção para uma dimensão do envelhecimento que não está sendo muito considerada. A demarcação dos 60 anos como o marco que define quem é ou quem não é idoso faz com que um número significativo de pessoas, que tem 60 anos e que são plenamente independente, não sejam visibilizada nas suas necessidades e neste sentido a discussão que une geração e território poderia ser o espaço de contribuição das ciências sociais e mais especialmente da antropologia. A maioria das pessoas que frequentam o lar do Vô João fazem parte deste grupo invisibilizado.

\section{Antropologia, envelhecimento e território}

Como foi dito anteriormente, as idosas que frequentam o lar têm perfis bastante variados, mas algumas queixas são reincidentes, em especial, a solidão. $\mathrm{Na}$ fala das profissionais da casa, foi unanimidade apontarem o descuido das famílias, a falta de paciência com suas idosas e - de maneira velada - a exploração econômica das mesmas, ao se apropriarem de suas rendas, como fatos corriqueiros. Em contraposição, ainda na fala das funcionárias, é na instituição que elas recebem carinho, atenção e são cuidadas, reforçando o que dizem alguns estudos sobre idosas que vivem em asilos situados em áreas urbanas. Neste caso, a literatura mostra que o discurso é o mesmo, independente da 
área. A família não tem tempo e nem paciência com suas idosas e muitas vezes a aposentadoria é motivo de brigas e rivalidades, igualando-se aos discursos relativos aos espaços urbanos.

Por outro lado, ao falarmos com famílias da Guia cujos idosos não frequentam a instituição-dia, encontramos outros discursos. Alguns familiares afirmaram que não deixariam suas mães ou pais irem para o lar, pois temiam que eles não fossem bem cuidados. As idosas e os idosos com os quais conversamos afirmavam que estavam bem em suas casas e tinham muito o que fazer. As idosas, em especial, afirmavam que as filhas e netas precisavam delas. Como pano de fundo existia a necessidade de afirmarem que eram autônomas e independentes e não precisavam ser cuidadas. Com relação a aposentadoria, apesar dos relatos das funcionárias do lar, que certamente revelam a realidade de alguns, também encontramos situações em que por conta da aposentadoria as idosas e os idosos eram valorizados e respeitados no grupo familiar. Esta questão, sobre a importância da independência financeira dos idosos para a boa relação intergeracional nas famílias foi discutido por Segalen (2001) e mereceria maior aprofundamento.

Algumas falas chamaram atenção não por fugirem totalmente a este padrão, mas por acrescentarem alguns ingredientes que nos ajudam a pensar. A narrativa de dona Rosa, neste caso, é muito interessante. $^{8}$

Dona Rosa tinha 67 anos, estava sempre arrumada, cabelos e unhas bem cuidados e com batom nos lábios. Confesso que me perguntava o que aquela mulher fazia ali. Em nossa conversa ela não faz nenhuma queixa de saúde e afirma que veio para o lar por vontade própria. Até há pouco tempo morava em João Pessoa onde cresceu, casou e criou seus filhos. Só saiu porque todos se casaram e o último mudou de estado. Apesar de adorar o lugar que morava, os filhos [e ela também] acharam que não era seguro uma senhora de sua idade morar sozinha e a alternativa que lhe pareceu mais adequada foi vir para a casa da filha que mora em Lucena. Soube do lar por uma conhecida e quis conhecer. Entre outras coisas, ela diz: 
aqui pelo menos eu tenho com quem conversar. Lá, na casa da minha filha, não tem nem vizinho. De um lado é um muro, do outro uma fabrica, na frente é tipo um hotel, a gente não vê ninguém. Olho prum lado, ninguém; olho pro outro, ninguém...Bom mesmo era na minha casa. Lá, todo dia eu terminava meu serviço e ia conversar com minhas vizinhas; um dia na casa de uma, outro dia na casa de outra, as vezes ficávamos na calçada... ali é que era bom. Eu to até pensando em voltar (Rosa 67 anos).

A narrativa de dona Rosa provocou minha curiosidade. Diferentemente do que se poderia supor, era em João Pessoa que ela encontrava, no convívio amistoso com a vizinhança, seu espaço de lazer e sociabilidade. Vir para uma cidade pequena não significou ter mais companhia, ter uma rotina mais tranquila, ou uma melhor qualidade de vida. Num dado momento eu pergunto: "sua filha cuida da senhora?" e ela prontamente responde: "eu não preciso que ninguém cuide de mim; eu cuido de mim; só queria que me chamassem para os cantos". Na medida em que dona Rosa conta sua história fica claro que ela, há muito tempo, toma conta da própria vida. Ficou viúva quando os filhos ainda eram crianças e nunca mais voltou a se casar. Trabalhou durante 30 anos em uma pré-escola e só saiu quando se aposentou. Foi com o seu trabalho e a aposentadoria do marido que criou os 4 filhos. Esta é uma, no meio de tantas outras histórias. O que a torna especial, no meu entendimento, é que ela 'bagunça' alguns paradigmas tanto no que diz respeito à dicotomia rural/urbano, como no que se diz a respeito as idosas.

Dona Rosa morava na capital e este fato não era um motivo de queixa. Ao contrário, percebemos pela sua fala que vir para Lucena foi uma ruptura na sua dinâmica social. Quando ela diz que agora "nem vizinho tem" ela está, na verdade, se lamentando de ter deixado para trás o "seu mundo". Sua queixa nos fala de um corte espacial e também simbólico. A vizinhança simboliza a dinâmica da vida cotidiana e a rede de sociabilidade que ela construiu ao longo do tempo e que atribuía sentido à sua rotina e que de uma hora para outra são des- 
cartadas. Por outro lado, ela mesma afirma que não se sentia segura permanecendo em João Pessoa, por ser mulher e idosa.

Ao discutir envelhecimento e memória entre idosos na cidade de Porto Alegre, Eckert (2002) nos traz uma questão semelhante. Suas entrevistadas se queixam que hoje, diante da violência, não podem mais sentar na calçada, à noite, para conversar com as vizinhas. Neste caso a ruptura também acontece, mas devido transformações decorrentes 'do mundo atual'. Neste caso a ruptura é temporal. Está se falando de outro tempo, que não é mais o delas. Neste caso, os espaços atribuem sentido ao viver. Quando ocorrem cortes, por fatores diversos, também são vividos como cortes na vida. Esta é uma questão que a antropologia poderia problematizar mais. Até que ponto não naturalizamos estes cortes e fazendo isso, de alguma forma confirmamos 'a falta de sentido' da vida do idoso?

Alguns estudos sobre terceira idade ou envelhecimento, numa perspectiva antropológica, atrelam as categorias gênero, condição social, etnia, mas raramente a ideia de território está presente. Existem estudos sobre o idoso na área rural (Heck \& Langdon 2002), ou então o idoso nos centros urbanos (Eckert 2002), conforme referido acima. Mas nestes casos a especificidade do local (ser rural ou ser urbano) surge como pano de fundo, como cenário, para outras questões, como relações de gênero, aposentadoria, violência, espaços de sociabilidade, memória, entre outras, serem pensadas e problematizadas. A literatura sobre envelhecimento no âmbito das ciências sociais não tem priorizado a discussão que dialoga território e envelhecimento.

Se concordamos com Cerqueira et al. (2011) e cremos que o "o referencial identitário do envelhecer pode ser construído a partir da cotidianidade, ou seja, de relações vividas no universo local, na rua, no bairro, na cidade" (Cerqueira et al. 2011:180) faz sentido pensarmos mais seriamente sobre o cotidiano do idoso e qual a real causa de sua limitação. Dona Rosa precisou deixar sua casa, suas amizades e sua rotina de vida, mesmo sendo independente economicamente e autônoma, devido à fragilidade da segurança pública. Neste caso, ela não tinha 
nenhuma deficiência, mas existia uma deficiência na política pública de segurança que a obrigou a mudar sua rotina de vida e frequentar um lar-dia para idosos, apenas para reestabelecer relações sociais.

Por outro lado, moradoras da comunidade da Guia relatavam que os maiores impedimentos para cuidar da própria saúde era a precariedade dos transportes públicos. Mesmo não sendo muito distante, elas não podiam se deslocar com agilidade para o centro de Lucena, para pegar remédio na farmácia ou para outra emergência, pois o transporte público só passava na Guia três vezes por dia, às 7:00 horas, ao meio dia e às 18:00 horas. Para uma internação ou um exame de imagem teriam que ir para Cabedelo, o que implicava transporte até o terminal da Balsa e em seguida meia hora de travessia. Sendo assim, o sistema de transportes também gera uma limitação no grau de independência que interfere negativamente na construção de estratégias para dar conta das demandas cotidianas e para a resolução de situações emergenciais.

As situações acima descritas abrem espaço para outras reflexões sobre dependência/ independência e deficiência. Se é fato que o envelhecimento acarreta algum tipo de limitação física, em diferentes gradações, esta pode se transformar em uma limitação no grau de independência por conta da falta de aparatos institucionais e políticas públicas sensíveis a estas questões. Ler o número e tomar um ônibus pode ser algo simples ou limitador, dependendo das políticas públicas existentes. Recentemente tive uma aluna deficiente visual e conversando percebi a dificuldade que era para ela saber a parada que deveria descer e ao mesmo tempo me dei conta de como esta questão poderia ser facilmente resolvida se existisse um sistema de áudio no ônibus, por exemplo, que avisasse a próxima parada. Um idoso pode se locomover um pouco mais lentamente e isso pode (ou não) ser um obstáculo para sua autonomia na medida que o tempo dos sinais de trânsito não estão programados para funcionarem levando esta variável em consideração. Poderíamos pensar inúmeras outras situações que acabam limitando a possibilidade de inserção social de pessoas com deficiência ou idosas . 
O trabalho 'Envelheço na cidade: sobre cotidianos do envelhecer na região central de São Paulo' (Cerqueira et al. 2011) nos contempla com uma abordagem que parte do olhar do idoso no seu espaço de sociabilidade e trabalho. A partir da observação de idosos em diferentes atividades laborais, no centro de São Paulo, os autores conseguem captar as diversas facetas do cotidiano que tanto visibilizam o esforço para superar as limitações físicas, mas também mostram o aspecto prazeroso de autoestima, principalmente com relação a atividades laborais. Neste olhar, não preconceituoso, é possível perceber onde os idosos em questão vão buscar sentido para sua vida, apesar das limitações, das dores, da solidão. Este parece ser um caminho promissor...

Como nos dizem Diniz, Barbosa \& Santos "A deficiência traduz, portanto, a opressão ao corpo com impedimentos: o conceito de corpo deficiente ou pessoa com deficiência devem ser entendidos em termos políticos e não mais estritamente biomédicos" (2009:65). Se o modelo biomédico identifica a pessoa deficiente como alguém que tem alguma inadequação para a sociedade, o modelo social vai mostrar que a inadequação está na sociedade (Diniz, Barbosa \& Santos 2009). Esta discussão está muito em sintonia com a discussão atual sobre políticas de cuidado. Quando pensamos a deficiência através do idoso, incluímos todos como integrantes do mesmo grupo. Todos (se tudo der certo) envelheceremos e vivenciaremos algum grau de limitação física que pode ser equiparada a uma deficiência. Nesta lógica de raciocínio podemos fazer dois tipos de desdobramentos: 1º, a deficiência não é algo distante, mas sim presente na perspectiva de futuro de todas as pessoas; $2^{\circ}$, assim como o cuidado, que não é próprio a apenas alguns segmentos etários (normalmente relacionado à infância e à velhice) mas inerente a vida de todas as pessoas, a deficiência também e sendo assim deve ser pensada como política pública. Uma política pública do cuidado tira o cuidar da invisibilidade e da ordem do privado e traz para o público, reconhecendo que está presente em todas as dimensões da vida. Da mesma forma, pensarmos a 
deficiência em sua perspectiva social é reconhecer que a sociedade, em seu olhar limitado a uma perspectiva de 'normalidade', cria vidas deficientes. Cotidianamente pessoas idosas, em espaços urbanos e rurais, são limitadas e mutiladas em suas possibilidades de independência e autonomia. É necessário darmos mais visibilidade a estas questões e pensarmos politicamente sobre elas.

\section{Notas}

1 Agradecimento a CAPES, por viabilizar a pesquisa através do edital universal Processo: 447046/2014-4; Projeto: "Etnografando o cuidado: observando o cuidado com o idoso nas relações familiares e no serviço de saúde a partir de uma etnografia na comunidade de Nossa Senhora da Guia no município de Lucena/PB”; Instituição de Vínculo: Universidade Federal da Paraíba/UFPB-PB.

2 Parte deste texto foi apresentado no Encontro Regional de Antropologia realizado em Maceió, em 2015.

3 Nome fictício.

4 Trata-se do trabalho “'Aqui Eu Nem Tenho Vizinho': Reflexões preliminares sobre os sentidos atribuídos a uma instituição para idosos em um espaço 'mais ou menos' rural”, apresentado na Reabanne, 2015, em Maceió, no GT 21: Etnografias urbanas: campos, fronteiras, diferenças.

5 Muitos moradores de Lucena trabalham ou estudam em Cabedelo ou em João Pessoa, o que os obriga a fazerem esta travessia diariamente;

6 Esta afirmação é polêmica, mas não será problematizada neste trabalho.

7 A discussão sobre cuidado é amparada pela perspectiva teórica feminista, pois incide fortemente nas questões de desigualdade de gênero. Sendo assim, optei utilizar o plural no feminino por uma questão lógica, já que grande parte do público que frequenta o lar de idosos é do sexo feminino e também por uma questão política, para dar visibilidade a esta questão de gênero.

8 A história de dona Rosa já foi citada num trabalho de minha autoria e só será retomada, de forma resumida, por conter elementos fundamentais para o argumento do trabalho.

\section{Referências}

ABRAMOVAY, Ricardo. 2003. O futuro das regiões rurais. Porto Alegre: UFRGS. 
CAMARANO, Ana Amélia. 2003. "Mulher Idosa: suporte familiar ou agente de mudança”. Revista de Estudos Avançados, *(*):35-64.

2005. "Final coments: Well Beyond 60 years of age, but how?" In: CAMARANO, Ana Amélia (ed.). Sixty plus: the elderly Brazilians and their new social roles, pp. 571-578. Rio de Janeiro: IPEA: Instituto de Pesquisa Aplicada.

CAMARANO, A. A. \& PASINATO, M. 1999. "Introdução”. In: CAMARANO, A. A. (ed.): Muito além dos 60: os novos idosos brasileiros, pp. 01-22. Rio de Janeiro: Ipea.

2004. "O envelhecimento populacional na agenda das políticas públicas". In: CAMARANO, A. A. (ed.): Os novos idosos brasileiros:muito além dos 60?, pp. 253-292. Rio de Janeiro: Ipea.

CAMARANO, A. A. et al. 2010. "As Instituições de longa permanência para idosos no Brasil”. In: CAMARANO, A. A. (ed.): Cuidados de longa duração para a população idosa: um novo risco social a ser assumido?, pp. 337-349. Rio de Janeiro: Ipea.

CARNEIRO, Maria José. 2008. "'Rural' como categoria de pensamento". Ruris, 2(1):9-39.

CERQUEIRA, M. et al. 2011. "Envelheço na cidade: sobre cotidianos do envelhecer na região central de São Paulo". In TRENCH, B. \&COSTA ROSA, T. E. (eds.): Nós e o Outro: envelhecimento, reflexões, práticas e pesquisa, pp. 159-182. São Paulo: Instituto de Saúde.

DINIZ, D., MEDEIROS,M. \& BARBOSA L. (eds.). 2010. Deficiência e Igualdade. Brasília: Editora letras Livres/ Editora UNB.

D., BARBOSA, L. \& SANTOS, W. 2009. "Deficiência, Direitos Humanos e Justiça”. SUR - Revista Internacional de Direitos Humanos, 6(11):65-77.

ECKERT, Cornelia. 2002. "A Cultura do Medo e as Tensões do Viver a Cidade: narrativa etrajetória de velhos moradores de Porto Alegre". In MINAYO, Maria Cecília (ed.): Antropologia, saúde e envelhecimento, pp. 73-102. Rio de Janeiro: Editora FIOCRUZ.

DEBERT, Guita Grin. 1999. A reinvenção da velhice: socialização e processos de reprivatização do envelhecimento. São Paulo: Editora da Universidade de São Paulo/FAPESP. 2016. "Migrações e o Cuidado do idoso". Cadernos Pagu, 46:129-149.

GUIMARÃES, N., HIRATA, H. \& SUGITA, K. 2011. "Cuidado e Cuidadoras: o trabalho de care no Brasil, França e Japão". Sociologia E Antropologia, 1(1):151-180.

HECK, R. M. \& LANGDON, J. 2002. "Envelhecimento, Relações de Gênero e o Papel das Mulheres na Organização da Vida em uma Comunidade Rura". In MINAYO, Maria Cecília (ed.): Antropologia, saúde e envelhecimento, pp. 129-151. Rio de Janeiro: Editora FIOCRUZ.

LINS DE BARROS, Mirian. 2006. "Trajetória dos Estudos de Velhice no Brasil”. Sociologia, Problemas e Práticas, (52):109-132.

LONGHI, Marcia R. 2018. "Eu tô fazendo certo, tô não? Envelhecimento, políticas de saúde e relações de cuidado". In MALUF, S. W. \& SILVA, E. Q. (eds.): Estado, Políticas e Agenciamentos Sociais em Saúde: etnografias comparadas, pp. 189204. Florianópolis: Editora da UFSC. 
PALOMO, M. \& TERRÓN, M. 2015. Interdependencias - Una Aproximacion al mundo familiar del cuidado. (http://argumentos.sociales.uba.ar; s/d de acesso).

SEGALEN, Martine. 2001. "Entrevista com Martine Segalen: Qual é a Antropologia do parentesco e da família no século XXI? Um diálogo franco e brasileiro com Martine Segalen”. Horizontes Antropológicos, 7(16):277-295.

SORJ, B. \& FONTES, A. 2012. "O care como um regime estratificado: implicações de gênero e classe social”. In HIRATA, H. \& GUIMARÃES, N. (eds.): Cuidado e Cuidadoras: As várias faces do trabalho do Care, pp. 103-116. São Paulo: Editora Atlas S. A.

ZIRBEL, Ilze. 2016. Uma Teoria Político-Feminista do Cuidado. Tese de Doutorado. Florianópolis: UFSC.

\begin{abstract}
The present text has the objective of making some considerations from the interweaving of the categories care, old age, gender, social deficiency and territory. The inspiration comes from the field work carried out in a community in the municipality of Lucena (state of Paraiba) and the observation carried out in an institution for the elderly, also located in Lucena. Based on some reflections about the existence of an institution for the elderly in an area close to the rural area, I problematize some preconceptions about old age and the diversity presented by the interlocutors and the richness of the literature, I conclude proposing to rethink about the care category and expand the possibilities of defining old age.
\end{abstract}

Keywords: Care, Old Age, Gender, Deficiency.

Recebido em outubro de 2018.

Aprovado em dezembro de 2018. 